\title{
Die Olympischen Ringe verbinden unseren Sport in all seiner Vielfalt
}

\section{Veronika Rücker}

Die Sportfunktionärin Veronika Rücker ist Vorstandsvorsitzende des Deutschen Olympischen Sportbundes. Neben ihrer beruflichen Karriere als Sportwissenschaftlerin und Diplom-Sportlehrerin war sie für lange Zeit aktive TennisSpielerin und A-Trainerin des Deutschen Tennis Bundes und wurde 2019 mit dem DTB-Award ausgezeichnet.

Der Deutsche Olympische Sportbund (DOSB) ist das Dach des organisierten Sports in Deutschland, unter dem sich zahlreiche sportliche und sportpolitische Themen sammeln. Zugleich ist er das Nationale Olympische Komitee für Deutschland (NOK). 2006 haben die beiden Vorgänger-Organisationen - „Deutscher Sportbund“ und „NOK“ - ihre Kräfte, Aufgaben und Ziele gebündelt und sind zum DOSB zusammengewachsen. Wir engagieren uns für den Vereinssport und sind die Stimme einer Gemeinschaft des Sports mit 27 Millionen Mitgliedschaften in 90.000 Vereinen. Zugleich stehen wir für die Olympische Idee und sind Teil der olympischen und paralympischen Bewegung.

Unser Sportverständnis ist in allen Bereichen durch die olympischen Werte Leistung, Freundschaft, Fair Play und Respekt geprägt. Das zeigt unser Logo auf wunderbar einfache und für jeden verständliche Weise: Die vier Buchstaben DOSB wirken wie die festen Säulen der Basis, der bunten Vereinslandschaft von Sportdeutschland, und eng dazu gehören die ineinander verschlungenen fünf Olympischen Ringe, die in fünf Farben für weltweite Verbundenheit, für ein weltumspannendes, friedliches Miteinander der Verständigung stehen.

Uns im DOSB begeistert der Sport in seiner Vielfalt und wir schätzen seine verbindende Kraft. Diese Begeisterung leben und fördern wir - und das in langer Vereinstradition. Wir wertschätzen alle: von der Olympiasiegerin bis zum Freizeitsportler. Wir zollen allen unsere Anerkennung und Respekt und fördern die Leistungsfähigkeit unserer Athlet"innen. Wir unterstützen dabei all diejenigen, die ohne Manipulation maximalen Erfolg im Spitzensport wollen. Zugleich unterstützen wir auch jene, die in ihrer Freizeit den Wettkampf mit anderen oder mit sich selbst suchen oder aus reiner Freude sportlich aktiv sind. 
Aus der Größe dieser Gemeinschaft in Sportdeutschland erwächst zugleich Verantwortung. Der DOSB versteht sich als ein wichtiger Teil der Zivilgesellschaft und bringt sich aktiv in gesellschaftliche Entwicklungen ein. Als Stimme des Sports entwickeln wir für zentrale Herausforderungen Lösungen und setzen uns für die gesellschaftliche Anerkennung des Sports und dessen Leistungen ein. Wir vertreten die Interessen des Sports als eine der tragenden Säulen der Gesellschaft - lokal wie regional, national wie international.

Die Integrität des Sports ist unser höchstes Gut. Der Sport basiert auf Werten wie Ehrlichkeit, Fair Play und Respekt - diese leiten unser selbstbestimmtes und demokratisches Handeln. Wir setzen uns für einen doping- und korruptionsfreien Sport ein. Und wir wollen Erfolg, aber nicht um jeden Preis.

Die Begeisterung für den Sport in all seinen Facetten wird im Verein gelegt. Ich bin davon zutiefst überzeugt, weil ich es selbst so erlebt habe. Diese Erfahrungen helfen mir auch in meiner Aufgabe als Vorstandsvorsitzende des DOSB. Leistung, Freundschaft, Fair Play und Respekt - das ist die Basis, und diese Werte sind im Verein und im olympischen Spitzensport absolut vergleichbar. Im noch so kleinen Verein findet sich schon das wieder, was die Olympische Idee ausmacht.

Diesen Zusammenhang wollen wir noch stärker herausstellen. Denn das strahlt selbstverständlich auch aus auf all die Projekte und Tätigkeiten im Dachverband des deutschen Sports. Von der Unterstützung der Vereine bis hin zur Entsendung der deutschen Olympiamannschaft (Team D) zu den Olympischen Spielen versuchen wir, die Olympische Idee mit Leben zu füllen, weiterzuentwickeln und mitzutragen.

Ich bin im Verein groß geworden. Ich habe Tennis gespielt und spiele bis heute noch in meinem Verein. Meine Begeisterung für den Sport im Allgemeinen und für Tennis im Besonderen ist bereits früh entstanden. Ich habe weite Teile meiner Kindheit und Jugend auf dem Tennisplatz verbracht. Dabei ist auch etwas gereift, was ich später erst erkannt habe und was der DOSB als sein Grundverständnis und Leitbild festgeschrieben hat.

Sport ist für viele Menschen Lebensinhalt und Lebensqualität, er bereichert das Leben. Sport kann Tradition und Trend sein. Jeder kann ihn für sich allein oder in einer Mannschaft ausüben, im Ehrenamt oder auch als Beruf. Aber immer gilt: Sport ist eine Basis für gemeinsame Werte und Leidenschaften. Sport bringt Menschen zusammen - unabhängig von persönlichen Überzeugungen und Voraussetzungen, von Herkunft, Geschlecht, Neigung oder Alter. Letztlich kann Sport Motor sein für das 
soziale Zusammenleben in gesellschaftlicher Vielfalt. Für uns gilt damit auch: Jeder Sportverein an der Basis ist Teil der olympischen Bewegung.

Unsere Teams bei internationalen Sportevents sind Aushängeschilder und Botschafter für unser Land und für die Olympische Idee, die wir leben, fördern und unterstützen. Als Nationales Olympisches Komitee für Deutschland arbeiten wir deshalb auch in einem weltweiten Netzwerk. Wir handeln entsprechend der Olympischen Charta und treten für Erfolge ein, die fair errungen werden.

Olympische und Paralympische Spiele schaffen magische, verbindende Momente und begeistern die Menschen weltweit. Das habe ich selbst erlebt, und gerade vor dem Hintergrund meiner eigenen Erlebnisse habe ich eine ganz eigene Perspektive auf die Spiele. Ich habe es zwar als Tennisspielerin nicht so weit gebracht, aber trotzdem blicke ich auf eine längere, ganz persönliche olympische Geschichte zurück. Im Jahr 1992 habe ich in Barcelona erstmals Olympische Spiele live erlebt - und war von da an mit dem „Olympischen Virus“ infiziert. Seitdem habe ich als Touristin zahlreiche Spiele mit all den magischen, verbindenden Momenten erleben dürfen und bin immer wieder aufs Neue fasziniert.

Die Erinnerungen sind vielfältig und gehen weit über den Sport hinaus. Während der Spiele in Sydney 2000 beispielsweise haben wir uns direkt in der Stadt auf einem Campingplatz eingemietet. Diese 14 Tage inmitten olympischer Stimmung werde ich nie vergessen. Ich habe das großartige Kulturprogramm in der Innenstadt genossen. Jeden Abend, bis tief in die Nacht hinein, waren Menschen aller Nationen unterwegs. Sie haben sich an Aufführungen beteiligt und ausgetauscht, natürlich auch über Sport, aber vor allem über Gott und die Welt. In friedlicher Atmosphäre haben wir gemeinsam ein buntes, einmaliges und unvergessenes Fest gefeiert.

Olympia kann Perspektiven verändern. Mich hat auch dieser Rollenwechsel fasziniert und tut es immer noch: von jemandem, der die Olympische Bewegung als Touristin aufsaugt und genießt, zu jemandem, der mit Verantwortung dafür trägt, dass die Werte dieser Bewegung weitergetragen und geteilt werden. Ich empfinde das nach wie vor als eine besondere Ehre.

Im Jahr 2016 war ich als damalige Direktorin der Führungs-Akademie des DOSB zwar als Touristin in Rio de Janeiro, aber gelegentlich schon in offizieller Funktion im Deutschen Haus tätig. Zwei Jahre später, bei den Olympischen Winterspielen in Pyeongchang 2018, war ich dann zum ersten Mal Teil der Delegationsleitung des Team Deutschland. Damit war es auch meine Aufgabe, für die Umsetzung und Einhaltung der Olympischen Werte einzutreten. So trug ich Verantwortung dafür, dass sich das 
Team vorbildlich verhielt und dass all das, was der DOSB für sein Team D propagiert, auch gelebt wird.

Dafür versuchen wir, die bestmöglichen Bedingungen für unsere Leistungssportler*innen zu schaffen und den größten Talenten eine optimale und verantwortungsvolle Förderung zu bieten. Dafür unterstützen wir die Athlet*innen in ihrer Persönlichkeitsentwicklung und unterstützen sie in ihrer Lebens- und Karriereplanung. All das in meiner heutigen Funktion begleiten zu dürfen, ist ein großes Privileg, das ich sehr zu schätzen weiß.

Ich bin deshalb aus eigenem Erleben fest überzeugt, dass der organisierte Sport im Verein eine wesentliche Säule der Gesellschaft in einer zunehmend globalisierten Welt darstellt. Die Sportvereine leisten unschätzbar wertvolle Arbeit mit ihrem Beitrag zu Bildung, Gesundheit, sozialer Integration und Inklusion im und durch Sport, denn dieser prägt die Lebenswelt von Menschen positiv und schafft Lebensqualität. Mit internationalen Begegnungen und Wettkämpfen trägt er zudem zu Frieden und Völkerverständigung bei. Deswegen setzen wir uns dafür ein, dass der Sport die Wahrnehmung und Anerkennung erhält, die er verdient.

Wir sind Teil einer globalen Sportgemeinschaft und tragen zur Entwicklung des Sports auf der ganzen Welt bei. Deshalb wollen wir auch große Sportveranstaltungen nach Deutschland holen. Wir wollen die Bevölkerung überzeugen, dass wir nachhaltige, verantwortungsvolle und vor allem begeisternde Gastgeber sind, die gerne die Sportwelt zu Gast in Deutschland begrüßen.

Die Strahlkraft der Olympischen Ringe, des bekanntesten Markenzeichens überhaupt, können bei alledem helfen. Künftig könnten sie in allen Sportvereinen, an möglichst vielen Sport- und Wettkampfstätten oder Stützpunkten, auf allen Straßenschildern und Wegweisern, auf das bunte, den ganzen Sport verbindende Band hinweisen: Wir alle stehen für die Olympische Idee und sind Teil der olympischen und paralympischen Bewegung.

Leben wir gemeinsam die Olympischen Werte und lassen wir möglichst viele an dieser Begeisterung teilhaben! 